:::: Helmholtz-Zentrum

$\because:$ Geesthacht

Zentrum für Material- und Küstenforschung

\title{
Original
}

Shi, C.; Yao, F.; Huang, J.; Han, G.; Li, Q.; Khan, M.; Feng, Y.; Zhang, W.: Proliferation and migration of human vascular endothelial cells mediated by ZNF580 gene complexed with mPEG-b-P(MMD-coGA)-g-PEI microparticles

In: Journal of Materials Chemistry B (2014) Royal Society of Chemistry

DOI: 10.1039/c3tb21601b 
Cite this: J. Mater. Chem. B, 2014, 2, 1825

Received 14th November 2013 Accepted 4th January 2014

DOI: $10.1039 / c 3 t b 21601 b$

www.rsc.org/MaterialsB

\section{Proliferation and migration of human vascular endothelial cells mediated by ZNF580 gene complexed with mPEG-b-P(MMD-co-GA)-g-PEI microparticles}

\author{
Changcan Shi, ${ }^{a}$ Fanglian Yao, ${ }^{\text {abc }}$ Jiawen Huang, ${ }^{d}$ Guoliang Han, ${ }^{d}$ Qian Li, ${ }^{a}$ \\ Musammir Khan, ${ }^{a}$ Yakai Feng ${ }^{\star a b c}$ and Wencheng Zhang ${ }^{\star e}$
}

Herein, we developed a novel biodegradable gene carrier for rapid endothelialization of endothelial cells (ECs) in vitro. Three triblock amphiphilic copolymers, methoxy-poly(ethylene glycol)-block-poly(3(S)methyl-2,5-morpholinedione-co-glycolide)-graft-polyethyleneimine (mPEG-b-P(MMD-co-GA)-g-PEI) with different 3(S)-methyl-2,5-morpholinedione and glycolide contents were synthesized. Microparticles (MPs) were obtained via self-assembly of these copolymers. The hydrophobic core composed of $\mathrm{P}(\mathrm{MMD}-\mathrm{co}-\mathrm{GA})$ segments provide crosslinking points for numbers of PEG and short PEI chains to form a highly hydrophilic and positively charged corona/shell of MPs. Using these MPs, potential genes (ZNF580) for rapid endothelialization were efficiently transported into EA.hy926 cells. Because of the hydrophilic PEG chains and low molecular weight PEI in the triblock copolymers, the cytotoxicity of these MPs and their complexes with pEGFP-ZNF580 was decreased significantly. The transfection efficacy of MPs/pEGFP-ZNF580 complexes was as high as LipofectamineTM 2000 reagent to EA.hy926 cells in vitro. The proliferation and migration of EA.hy926 cells were improved greatly by the expression of pEGFP-ZNF580 after 60 hours. Our results indicated that the mPEG- $b$-P(MMD-co-GA)-g-PEI based MPs could be a suitable non-viral gene carrier for ZNF580 gene to enhance rapid endothelialization.

\section{Introduction}

In modern society, atherosclerotic vascular diseases which include coronary and peripheral arterial diseases are the major causes of morbidity and mortality. ${ }^{1}$ In the treatment of occluded coronary arteries, coronary bypass surgery is one of the most

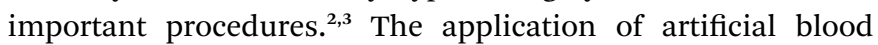
vessels is increasing significantly, ${ }^{4}$ but many problems such as thrombosis, intimal hyperplasia and low long-term patency rate are encountered.5,6 The hydrophobicity of artificial blood vessels is one of the most important reasons accounting for these problems. ${ }^{7}$ To overcome this obstacle, many strategies have been developed, for example, collagen, heparin and poly(ethylene glycol) (PEG) have been widely used in the

\footnotetext{
${ }^{a}$ School of Chemical Engineering and Technology, Tianjin University, Tianjin 300072, China.E-mail: yakaifeng@tju.edu.cn

${ }^{b}$ Key Laboratory of Systems Bioengineering of Ministry of Education, Tianjin University, Tianjin 300072, China

${ }^{c}$ Tianjin University-Helmholtz-Zentrum Geesthacht, Joint Laboratory for Biomaterials and Regenerative Medicine, Tianjin 300072, China

${ }^{d}$ Graduate School of Tianjin Medical University, Tianjin 300070, China

${ }^{e}$ Department of Physiology and Pathophysiology, Logistics University of Chinese People's Armed Police Force, Tianjin 300162, China. E-mail: wenchengzhang@ yahoo.com
}

modification of artificial vessels. ${ }^{8-10}$ Recently, 2-methacryloyloxyethyl phosphorylcholine, ${ }^{11-13}$ gelatin ${ }^{14}$ and $\mathrm{PEG}^{5,15,16}$ were also used to improve the hydrophilicity and hemocompatibility of polycarbonate urethane scaffolds in our research group. Besides hydrophobicity, the lack of a living functional layer of endothelial cells (ECs) on the inner surface of artificial blood vessels is also an important key issue which must be concerned to keep long-term patency rate. ${ }^{7}$ In order to realize the rapid endothelialization of artificial blood vessels, many methods have been explored by researchers. Zhang et al. ${ }^{\mathbf{1 7}}$ prepared electrospun membranes with dual-delivery function of vascular endothelial growth factor (VEGF) and platelet-derived growth factor-bb (PDGF), which enhanced the ECs proliferation in comparison to vascular smooth muscle cells (VSMCs). Lin et al. ${ }^{18}$ also reported that the attachment of ECs onto stents and the rapid endothelialization could be enriched and accelerated by the anti-CD34 antibody. Zhu et $a .^{19}$ found that the EC regeneration can be improved by aminolysis and biomacromolecule immobilization on the polyurethane scaffolds.

There are lots of factors, such as VEGF, hepatocyte growth factor (HGF), fibroblast growth factor (FGF), angiopoietin-1 and matrix metalloproteinase (MMP), which can induce angiogenesis through stimulating the migration and proliferation of ECs. ${ }^{20,21}$ Among these factors, VEGF has been widely used to 
increase the endothelialization on the artificial blood vessel surface with many methods. ${ }^{22-24}$ Besides VEGF, we have studied another gene (ZNF580) for cell proliferation for many years. ${ }^{25}$ The expression of ZNF580 gene could be upregulated by $\mathrm{H}_{2} \mathrm{O}_{2}$ via the NF- $\mathrm{BB}$ signaling pathway. ${ }^{25}$ More importantly, ZNF580 gene plays an important role in the intervention of atherosclerosis and the process of migration and proliferation of ECs. ${ }^{26}$ Notably, compared with VEGF, ZNF580 gene not only promotes the proliferation of ECs, but also inhibits the proliferation of smooth muscles. Although ZNF580 gene has been proved to possess huge advantages in rapid endothelialization in vitro, ${ }^{26}$ to the best of our knowledge, the application of ZNF580 gene in artificial blood vessels remains unexplored.

In recent decades, gene therapy has become a research hotspot for its great potential as a future therapeutic strategy for clinical approaches to treat chronic diseases including but not limited to cancer, immunodeficiency, genetic disorders and atherosclerotic vascular diseases. ${ }^{27-30}$ Non-viral gene carriers play an important role in gene delivery for gene therapy. ${ }^{31}$ Polyethyleneimine (PEI), which is regarded as the "gold" standard for gene delivery, is one of the most effective non-viral gene carriers in vitro and in vivo because of its unique combination of high charge density and enhanced "proton sponge effect" in endolysosome. ${ }^{32}$ In general, high molecular weight PEI shows high transfection activity. Nevertheless, it is nondegradable ${ }^{33}$ and at the same time the high degree of toxicity of PEI to cells was caused by its membrane disruptive properties. ${ }^{34,35}$ Although many approaches, ${ }^{36}$ such as acetylation of $\mathrm{PEI}^{37}$ and incorporation of nontoxic derivatives, ${ }^{38,39}$ have been explored to reduce the genotoxicity of PEI, the transfection efficiency of the modified PEI decreased generally with the amino modification of PEI. ${ }^{40,41}$

Low molecular weight PEI generally exhibits much lower toxicity, but its transfection is inefficient. ${ }^{42}$ Considering the advantage of non-/low-toxicity of low molecular weight PEI, many efforts have been made to increase its transfection. ${ }^{43-45}$ However, the lack of gene carriers with both low toxicity and high transfection efficiency remains a long-lasting challenge for gene therapy. It is necessary to develop novel gene delivery systems to overcome this obstacle. In addition, it is of great interest to know whether it is possible to encapsulate ZNF580 gene into the delivery system to form novel gene microparticle complexes to improve the proliferation and migration of ECs.

The purpose of this paper is to prepare a novel gene carrier with low toxicity and gene/microparticle complexes with high transfection efficiency for ECs. The encapsulated ZNF580 gene complexes bring ZNF580 gene into ECs to promote its proliferation and migration. To realize this goal, we synthesized triblock methoxy-poly(ethylene glycol)-block-poly(3(S)-methyl2,5-morpholinedione-co-glycolide)-graft-polyethyleneimine (mPEG- $b$-P(MMD-co-GA)- $g$-PEI) copolymers. By self-assembly of amphiphilic triblock copolymers, microparticles (MPs) as a non-viral gene carrier were obtained. The hydrophobic core of these MPs was composed of P(MMD-co-GA) segments connected with numbers of PEG chains as the hydrophilic corona and short PEI chains as the cationic shell. Herein, MPEG was used as a hydrophilic constituent, ${ }^{\mathbf{4 6 , 4 7}}$ while glycolide (GA) and
3S-methyl-morpholine-2,5-dione (MMD) are commonly used monomers for the synthesis of non-toxic and biodegradable biomaterials. ${ }^{48,49}$ PEI $\left(\mathrm{M}_{w}=1800\right)$ was used to prepare the carrier for its low toxicity in spite of its low transfection efficiency. To improve the transfection capacity, many amphiphilic copolymer molecules were controlled to assemble and form microparticles with considerable positive charges. MPs/pEGFPZNF580 complexes with different positive charges were formed by adjusting the N/P molar ratios. Based on the MPs/pEGFPZNF580 complexes, pEGFP-ZNF580 can be delivered into ECs and expressed after release. The properties of MPEG- $b$-P(MMDco-GA)-g-PEI amphiphilic triblock copolymers, MPs and MPs/ pEGFP-ZNF580 complexes were characterized by different methods. The proliferation and migration ability of ECs transfected by MPs/pEGFP-ZNF580 complexes were also examined.

\section{Materials and methods}

\subsection{Materials}

3-(4,5-Dimethylthiazol-2-yl)-2,5-diphenyltetrazolium bromide (MTT), polyethyleneimine (branched PEI, $M_{\mathrm{w}}=1800$ ), mPEG $\left(M_{\mathrm{w}}=5000\right)$ and stannous octoate were purchased from SigmaAldrich (St. Louis, USA). GA was obtained from Foryou Medical Device Co., Ltd. (Huizhou, China). L-Alanine and chloroacetyl chloride were supplied by Aladdin Reagent Co., Ltd. (Shanghai, China). Dimethyl sulphoxide (DMSO) was purchased from Sigma (St. Louis, MO). Lipofectamine ${ }^{\mathrm{TM}} 2000$ reagent was purchased from Invitrogen (Grand Island, USA). BCA protein assay kit was purchased from Solarbio Science and Technology Co., Ltd. (Beijing, China). Rabbit anti-human ZNF580 polyclonal antibody and goat anti-rabbit IgG were purchased from Abcam (HK) Ltd. (Hong Kong, China). The pEGFP-ZNF580 was preserved by the Department of Physiology and Pathophysiology, Logistics University of Chinese People's Armed Police Force. MMD was prepared according to our previously reported method. ${ }^{50}$

\subsection{Synthesis of mPEG- $b$-P(MMD-co-GA)- $g$-PEI amphiphilic triblock copolymers}

2.2.1. Diblock copolymer of mPEG-b-P(MMD-co-GA). mPEG- $b$-P(MMD-co-GA) copolymer was prepared as reported previously $^{51}$ by ring-opening polymerization (ROP). Briefly, mPEG5000, MMD, GA and $\mathrm{Sn}(\mathrm{Oct})_{2}$ toluene solution were added in a flame-dried and nitrogen-purged flask. The flask was sealed and maintained at $150{ }^{\circ} \mathrm{C}$ for 12 hours. The copolymer was recovered by dissolving in chloroform and followed by precipitation in ice-cold hexane. The resultant precipitate was filtered and dried at room temperature in vacuum until constant weight. Finally, diblock copolymers named mPEG- $b$ $\mathrm{P}(\mathrm{MMD}-c o-\mathrm{GA})_{1}$, MPEG- $b$-P(MMD- $\left.c o-\mathrm{GA}\right)_{2}$ and MPEG- $b$-P(MMD$c o$-GA $)_{3}$ were obtained, where the subscripts 1,2 and 3 stand for different $\mathrm{MMD} / \mathrm{GA}$ contents in the copolymers as described in Table 1.

2.2.2. Triblock copolymer of mPEG- $b$-P(MMD-co-GA)- $g$-PEI. mPEG- $b$-P(MMD-co-GA) diblock copolymer (1 g) was dissolved in chloroform $(9.5 \mathrm{~mL})$, then the solution was transferred into a 
Table 1 Molecular weight of amphiphilic block copolymers and content of mPEG, MMD and GA in amphiphilic block copolymers

\begin{tabular}{|c|c|c|c|c|c|c|c|}
\hline Sample ID & \multicolumn{3}{|c|}{ Monomeric units content ${ }^{a} / \%$} & $M_{\mathrm{w}}^{b} / 10^{4}$ & $M_{\mathrm{w}}{ }^{a} / 10^{4}$ & $M_{\mathrm{w}}{ }^{c} / 10^{4}$ & $\mathrm{PDI}^{c}$ \\
\hline mPEG- $b$-P(MMD-co-GA $)_{2}$ & 50 & 17 & 33 & 1.20 & 1.15 & 1.18 & 1.35 \\
\hline mPEG- $b$-P(MMD-co-GA $)_{3}$ & 50 & 29 & 21 & 1.20 & 1.16 & 1.16 & 1.24 \\
\hline
\end{tabular}

dried constant pressure funnel $(20 \mathrm{~mL})$. Dibutyl tin dilaurate (DBTDL, $10 \mu \mathrm{L}$ ) and isophorone diisocyanate (IPDI, $1 \%$ toluene solution, $319 \mu \mathrm{L}$ ) were added in a three-necked flask, mPEG- $b$ $\mathrm{P}(\mathrm{MMD}-\mathrm{co}-\mathrm{GA})$ solution was added dropwise with stirring at $30{ }^{\circ} \mathrm{C}$ in $30 \mathrm{~min}$, and then reacted for 12 hours. The reaction mixture was added dropwise into $2.62 \mathrm{~mL}$ of $10 \%$ PEI toluene solution under a nitrogen atmosphere at $60{ }^{\circ} \mathrm{C}$ for 12 hours. When the solution was cooled to room temperature, triblock copolymers were obtained by precipitation in hexane as white flocculent precipitate. Here, mPEG- $b$-P(MMD-co-GA)- $g$-PEI ${ }_{1}$, mPEG- $b$-P(MMD- $c o$-GA)- $g$-PEI I $_{2}$ and MPEG- $b$-P(MMD-co-GA)- $g$ $\mathrm{PEI}_{3}$ were prepared from mPEG- $b$-P(MMD-co-GA $)_{1}$, mPEG- $b$ $\mathrm{P}(\mathrm{MMD}-c o-\mathrm{GA})_{2}$ and $\mathrm{mPEG}-b-\mathrm{P}(\mathrm{MMD}-c o-\mathrm{GA})_{3}$, respectively.

\subsection{Characterization of copolymers}

FT-IR spectra of the copolymers were obtained using a FT-IR spectrometer (Bio-Rad FTS-6000, USA). Moreover, ${ }^{1} \mathrm{H}$ NMR spectra of the synthesized polymers were recorded with a Bruker Avance spectrometer (AV-400, Bruker, Karlsruche, Gemany) operating at $400 \mathrm{MHz}$ in DMSO- $\mathrm{d}_{6}$. The average molecular weight $\left(M_{\mathrm{w}}\right)$ was determined by gel permeation chromatography (GPC, Malvern Viscotek, UK) in THF.

\subsection{Critical micelle concentration (CMC)}

The CMC values of triblock copolymers were determined using pyrene as an extrinsic probe. ${ }^{51,52} 12.4 \mathrm{mg}$ of pyrene was dissolved in acetone $(1000 \mathrm{~mL})$; the final concentration of the solution (A) was $6 \times 10^{-5} \mathrm{~mol} \mathrm{~L}^{-1} .100 \mathrm{mg}$ of polymer was dissolved in $10 \mathrm{~mL}$ triple-distilled water, the final concentration of copolymer solution was $10 \mathrm{mg} \mathrm{mL} \mathrm{m}^{-1}$. Then, a series of different concentrations from $10 \mathrm{mg} \mathrm{mL}^{-1}$ to $10^{-6} \mathrm{mg} \mathrm{mL}^{-1}$ of polymer solution (B) were prepared use the $10 \mathrm{mg} \mathrm{mL}^{-1}$ copolymer solution. $40 \mu \mathrm{L}$ of solution (A) was transferred into a tube and evaporated with $\mathrm{N}_{2}, 4 \mathrm{~mL}$ of solution (B) was added to the tube, and the final concentration of pyrene solution was $6 \times 10^{-7} \mathrm{~mol} \mathrm{~L}^{-1}$.

Steady-state fluorescence spectra were obtained with a Cary Eclipse fluorescence spectrometer. The ratios of excitation spectral intensities at $338 \mathrm{~nm}$ and $333 \mathrm{~nm}\left(I_{338} / I_{333}\right)$ were calculated and plotted against the logarithm of polymer mass concentration.

\subsection{Preparation and characterization of MPs/pEGFP- ZNF580 complexes}

2.5.1. Preparation of MPs. MPs were prepared using nanoprecipitation technology. ${ }^{53}$ Briefly, $10.0 \mathrm{mg}$ mPEG- $b$-P(MMD-co-
GA)-g-PEI copolymer was dissolved in $1 \mathrm{~mL}$ THF, the solution was added dropwise to $10 \mathrm{~mL}$ of triple-distilled water in a beaker. The mixture solution was stirred at room temperature for 24 hours to remove THF in a fume cupboard; the final volume of the solution was adjusted to $10 \mathrm{~mL}$ for further experiments.

2.5.2. Preparation of MP/pEGFP-ZNF580 complexes. pEGFP-ZNF580 gene was diluted to $1 \mu \mathrm{g} / 50 \mu \mathrm{L}$ with PBS buffer $(\mathrm{pH}=7.4)$. The complexes were prepared by adding MP solution ( $1 \mathrm{mg} \mathrm{mL} \mathrm{mL}^{-1}$ ) to plasmid solution (containing $1 \mu \mathrm{g}$ DNA) at various N/P molar ratios (0.5:1, $1: 1,5: 1,10: 1)$. N/P molar ratios were calculated from weight of polymer and pDNA, $\mathrm{N}$ content in the polymer and $\mathrm{P}$ content in pDNA. Before characterization and further experiments, the complexes were gently vortexed and incubated for $30 \mathrm{~min}$ at room temperature in a clean bench.

2.5.3. Size distribution and zeta potential. The size and zeta potential of MPs and MP/pEFGP-ZNF580 complexes were measured using a Zetasizer 3000HS (Malvern Instrument, Inc., Worcestershire, UK) at the wavelength of $677 \mathrm{~nm}$ with a constant angle of $90^{\circ}$.

2.5.4. Agarose gel electrophoresis. Agarose gel electrophoresis was performed to assess the DNA condensation ability of MPs. The MP/pEFGP-ZNF580 complexes with various N/P molar ratios ranging from 0.5 to 10 were prepared. The mixture solution was loaded into the agarose gel $(0.8 \%)$ containing $0.5 \mu \mathrm{g} \mathrm{mL}{ }^{-1}$ ethidium bromide. Electrophoresis was performed in $1 \times$ TAE buffer at $100 \mathrm{~V}$ for $40 \mathrm{~min}$, UV illuminator was used to indicate the retarded location of the plasmid DNA. ${ }^{54}$

2.5.5. In vitro release. The MPs/pEFGP-ZNF580 complexes with various $\mathrm{N} / \mathrm{P}$ molar ratios ranging from 5 to 20 , containing $20 \mu \mathrm{g}$ pEFGP-ZNF580 in each eppendorf tube, were incubated in $200 \mu \mathrm{L}$ of Tris- $\mathrm{HCl}$ buffer $(\mathrm{pH}=7.4)$ in a shaking incubator at $37{ }^{\circ} \mathrm{C}$. At different time intervals, the complex solutions were centrifuged at $12000 \mathrm{rpm},-4{ }^{\circ} \mathrm{C}$ for $20 \mathrm{~min}$; the supernatant was taken out carefully. Then, the complexes were resuspended with fresh Tris-HCl buffer and reincubated. The adsorption efficiency of plasmid DNA was obtained by measuring the extinction fluorescence with ethidium bromide, the supernatant was analyzed using a Cary Eclipse fluorescence spectrometer at an excitation wavelength of $524 \mathrm{~nm}$ and an emission wavelength of $582 \mathrm{~nm} .^{55}$

2.5.6. Morphology. The morphological studies of MPs and MP/pEFGP-ZNF580 complexes were performed on a JME100CXII transmission electron microscope (TEM, JEOL Ltd. Japan). Samples were prepared according to the following method. ${ }^{56}$ 


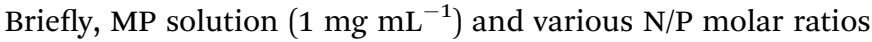
(0.5:1, $1: 1,5: 1,10: 1) \mathrm{MP} / \mathrm{pEFGP-ZNF580} \mathrm{solutions} \mathrm{were}$ applied onto a carbon-coated copper grid. Then the carboncoated copper grid was dried in the air for 10 hours before taking images.

\subsection{Transfection and cytotoxicity}

2.6.1. Cell culture. The human endothelial cell hybridoma line EA.hy926 cells purchased from American Type Culture Collection were cultured in high glucose DMEM supplemented $10 \%$ FBS in $5 \% \mathrm{CO}_{2}$ atmosphere at $37{ }^{\circ} \mathrm{C}$. The next day, the nonadherent cells were discarded, the adherent cells were cultured to confluence with medium exchanges being conducted every 3 days.

2.6.2. In vitro transfection. EA.hy926 cells were seeded in 24 -well plates at a density of $1 \times 10^{4}$ cell per well and cultured for 24 hours until $80-90 \%$ confluence. Before transfection, cells were incubated with serum-free medium for 12 hours. MP/ pEFGP-ZNF580 complexes with different concentrations and N/ $\mathrm{P}$ molar ratios $(1 \mu \mathrm{g}$ pEFGP-ZNF580 per well) were added into wells. After 4 hours, the medium was changed with fresh growth medium (10\% FBS DMEM). Then, cells were incubated to obtain considerable efficiency of gene transfection, the expression of green fluorescence protein (GFP) in cells was observed under an inverted fluorescent microscope at 12, 24 and 48 hours time points.

2.6.3. In vitro cytotoxicity. The cytotoxicity of MPs and MP/ pEFGP-ZNF580 complexes was evaluated by MTT assay using PEI $\left(M_{\mathrm{w}}=1800\right)$ as a control group. Briefly, EA.hy926 cells $(1 \times$ $10^{4}$ cell per well) were seeded in 96-well plates, and cultured for 24 hours until $80-90 \%$ confluence. Then, the medium was replaced with serum-free medium. After 12 hours, the medium was changed with fresh growth medium (10\% FBS DMEM). Different concentrations of MP solutions and various N/P molar ratio $\mathrm{MP} / \mathrm{pEFGP}-\mathrm{ZNF} 580$ complexes were added into the medium. After 48 hours, the supernatant was discarded, $20 \mu \mathrm{L}$ of MTT solution ( $5 \mathrm{mg} \mathrm{mL}^{-1}$ ) was added to each well and formazan crystals were allowed to form for another 4 hours. Then, the medium was removed carefully, $150 \mu \mathrm{L}$ of dimethylsulfoxide was added to each well, the plate was oscillated at low speed on a volatility instrument for $10 \mathrm{~min}$. Optical density (OD) was measured by an ELISA reader (Titertek multiscan MC) at the wavelength of $490 \mathrm{~nm}$. The relative cell viability (\%) was calculated using the following formula:

$$
\text { Relative cell viability }=\frac{\mathrm{OD} 490^{\prime}}{\operatorname{avg}\left(\mathrm{OD}_{4} 90 \mathrm{C}^{\prime}\right)} \times 100 \%
$$

where OD490' is the absorbance value of experimental wells minus zero wells, and avg(OD490C') is the average absorbance value of corrected control wells.

\subsection{Protein extraction and western blot analysis}

Western blot analysis was performed as reported previously. ${ }^{25}$ Briefly, cells were washed twice with $0.1 \mathrm{~mol} \mathrm{~L}^{-1} \mathrm{PBS}(\mathrm{pH}=7.4)$, and then were lysed in RIPA lysis buffer. The concentration of the lysate was determined by a BCA protein assay kit. Cell lysates containing $50 \mu \mathrm{g}$ of protein were subjected to SDS-PAGE by $15 \%$ polyacrylamide resolving gels. Proteins were transferred onto polyvinylidene fluoride membranes and incubated with rabbit anti-human ZNF580 polyclonal antibody after electrophoresis. Then, proteins were incubated with horseradish peroxidase conjugated to goat anti-rabbit IgG to assess the protein loading level, and then were incubated with enhanced chemiluminescence reagent and were exposed to film. The belt was analyzed using Image $\mathrm{J} 2.1, \beta$-actin antibody was used as a control.

\subsection{Wound healing assay}

The migration capability of EA.hy926 cells transfected by MP/ pEFGP-ZNF580 complexes was assessed using a scratch wound healing assay. ${ }^{57}$ Briefly, EA.hy926 cells were transfected with MP/pEFGP-ZNF580 complexes at the N/P molar ratio of 10; 48 hours later, the transfected cells were incubated to produce a nearly confluent cell monolayer in a 6-well plate. A linear wound was subsequently generated in the monolayer using a sterile 200 $\mu \mathrm{L}$ plastic pipette tip. Cellular debris was removed by washing with D-hanks buffer $(\mathrm{pH}=7.4)$. The migration process at different time points was monitored using an inverted microscope; the migration area was calculated using Image J 2.1 based on the images after 12 hours. The measurement of the wounded area was calculated using the following formula: wounded area $=$ length $\times$ width, and the percentage of migration area was calculated using the following formula: migration area $(\%)=($ wounded area - non-recovered area $) /$ wounded area. $^{58}$

\subsection{Statistical analysis}

All experiments were performed at least three times. Quantitative data are presented as the mean \pm S.D. Statistical comparisons were made with Student's $t$-test. $p$-Values $(<0.05)$ were considered to be statistically significant.

\section{Results}

\subsection{Synthesis of mPEG- $b$-P(MMD-co-GA)- $g$-PEI amphiphilic triblock copolymers}

The synthesis route of the mPEG- $b$-P(MMD-co-GA)- $g$-PEI copolymer is shown in Scheme 1 . The mPEG- $b$-P(MMD-co-GA) diblock copolymer was synthesized from MMD and GA by ROP. mPEG was introduced as the initiator to form a hydrophilic corona due to its high hydrophilicity and flexibility of the backbone. ${ }^{59}$ As an effective cyclopeptide, MMD was copolymerized with GA to form the polydepsipeptide structure. GA is widely used in poly(lactic acid-co-glycolic acid) copolymer to adjust its degradation rate. ${ }^{60}$ As shown in Table 1, the molecular weight of diblock copolymers and the content of MPEG, MMD and GA in copolymers were estimated by ${ }^{1} \mathrm{H}$ NMR and/or GPC.

As shown in Fig. 1, mPEG- $b$-P(MMD-co-GA) diblock copolymers presented a strong signal at $1104 \mathrm{~cm}^{-1}$ which indicated the ether groups of mPEG and ester groups (-O-CO-) of PGA and PMMD chain. The stretching frequency at $1689 \mathrm{~cm}^{-1}$ showed the secondary amide (-NH-) in PMMD segments; the signal at $1753 \mathrm{~cm}^{-1}$ was assigned to the carboxylate group 


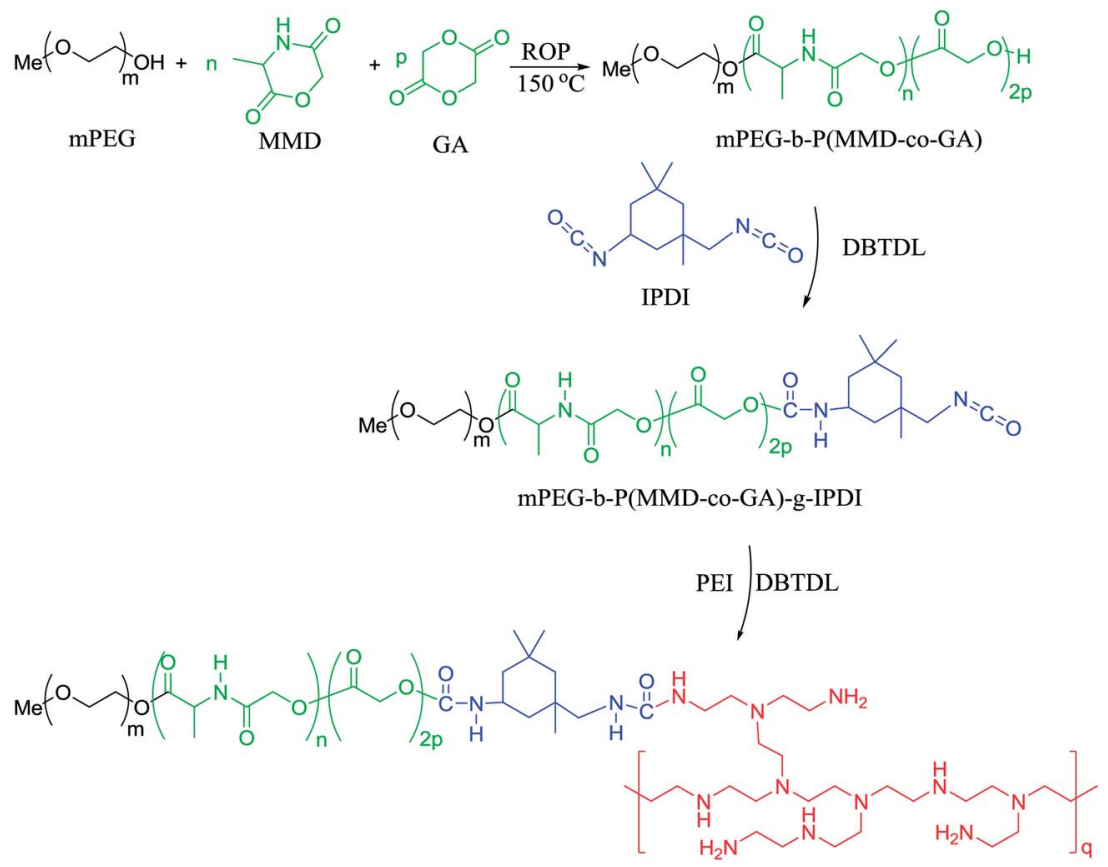

mPEG-b-P(MMD-co-GA)-g-PEI

Scheme 1 Synthesis route of mPEG-b-P(MMD-co-GA)-g-PEI amphiphilic triblock copolymer.

(-O-CO-); the signal at $2874 \mathrm{~cm}^{-1}$ was ascribed to methylene groups $\left(-\mathrm{CH}_{2}-\right)$ in the mPEG chain; the broad absorption band at $3289 \mathrm{~cm}^{-1}$ was assigned to the stretching of secondary amide $(-\mathrm{NH}-)$ groups in PMMD. The results suggested that mPEG- $b$ $\mathrm{P}(\mathrm{MMD}-\mathrm{co}-\mathrm{GA})$ diblock copolymers were synthesized successfully.

The ${ }^{1} \mathrm{H}$ NMR spectra of MMD, mPEG- $b$-P(MMD-co-GA $)_{1}$ and mPEG- $b$-P(MMD-co-GA)- $g$-PEI ${ }_{1}$ are illustrated in Fig. 2 . The peaks corresponding to $\mathrm{MPEG}, \mathrm{MMD}$ and GA could be clearly observed in the spectra and were assigned as follow: $1.56 \mathrm{ppm}$ $\left(\mathrm{NH}-\mathrm{CH}-\mathrm{CH}_{3}, 3 \mathrm{H}\right), 3.6-3.8$ ppm $\left(\mathrm{O}-\mathrm{CH}_{2}-\mathrm{CH}_{2}, 4 \mathrm{H}\right), 4.42 \mathrm{ppm}$ $\left(\mathrm{NH}-\mathrm{CH}-\mathrm{CH}_{3}, 1 \mathrm{H}\right), 8.5 \mathrm{ppm}(\mathrm{CH}-\mathrm{NH}, 1 \mathrm{H}),{ }^{51} 2.4-3.2 \mathrm{ppm}(-\mathrm{NH}-$ $\mathrm{CH}_{2}-\mathrm{CH}_{2}-$, PEI segment). ${ }^{45}$ These results suggested that mPEG-

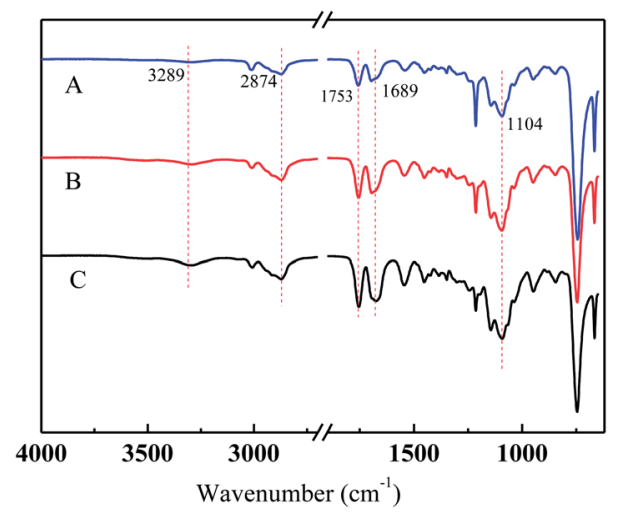

Fig. 1 FT-IR spectra of mPEG- $b-P(M M D-c O-G A)$ diblock copolymers. (A) $\mathrm{mPEG}-b-\mathrm{P}(\mathrm{MMD}-\mathrm{CO}-\mathrm{GA})_{1}$, (B) $\mathrm{mPEG}-b-\mathrm{P}(\mathrm{MMD}-\mathrm{CO}-\mathrm{GA})_{2}$, (C) $\mathrm{mPEG}-b-\mathrm{P}(\mathrm{MMD}-\mathrm{CO}-\mathrm{GA})_{3}$.
$b$-P(MMD-co-GA)- $g$-PEI triblock copolymers were synthesized successfully.

\subsection{Characterization of copolymers}

3.2.1. Measurement of CMC. The CMC values of the triblock mPEG- $b$-P(MMD-co-GA)-g-PEI copolymers were determined by a fluorescent determination method, the values are listed in Table 2. The results showed that the CMC values of triblock copolymers were very low compared with the ABA triblock copolymers reported by our research group previously. ${ }^{61}$ This might be attributed to the higher hydrophobicity produced by $\mathrm{P}(\mathrm{MMD}-\mathrm{co}-\mathrm{GA})$ segments because MMD and GA were introduced as hydrophobic constituents to form a polydepsipeptide structure core. The strong hydrogen-bond interaction in polydepsipeptides as well as between polydepsipeptides and GA reduces the fluidity of the core and enhances the stability of the micelle structure, ${ }^{62}$ and it might also lead to low CMC values (Fig. 3).

3.2.2. Morphology study of MPs and MPs/pEGFP-ZNF580 complexes. As shown in Scheme 2, amphiphilic triblock copolymers can assemble into core-shell structure MPs in aqueous solution. $\mathrm{P}(\mathrm{MMD}-\mathrm{co}-\mathrm{GA})$ hydrophobic segments of the amphiphilic triblock copolymer act as the core of MPs, while PEI and MPEG form the cationic shell and hydrophilic corona. Herein, mPEG is used as a water barrier that prevents proteins from approaching the surface, ${ }^{63}$ and to reduce the tendency of particles to aggregate by steric stabilization. ${ }^{64}$ Low molecular weight PEI is usually suggested to be used for gene delivery because of its low cytotoxicity compared with high molecular weight PEI, but it has almost no transfection efficacy. ${ }^{42}$ In order to overcome this obstacle, Teo et $a .^{65}$ prepared several short 

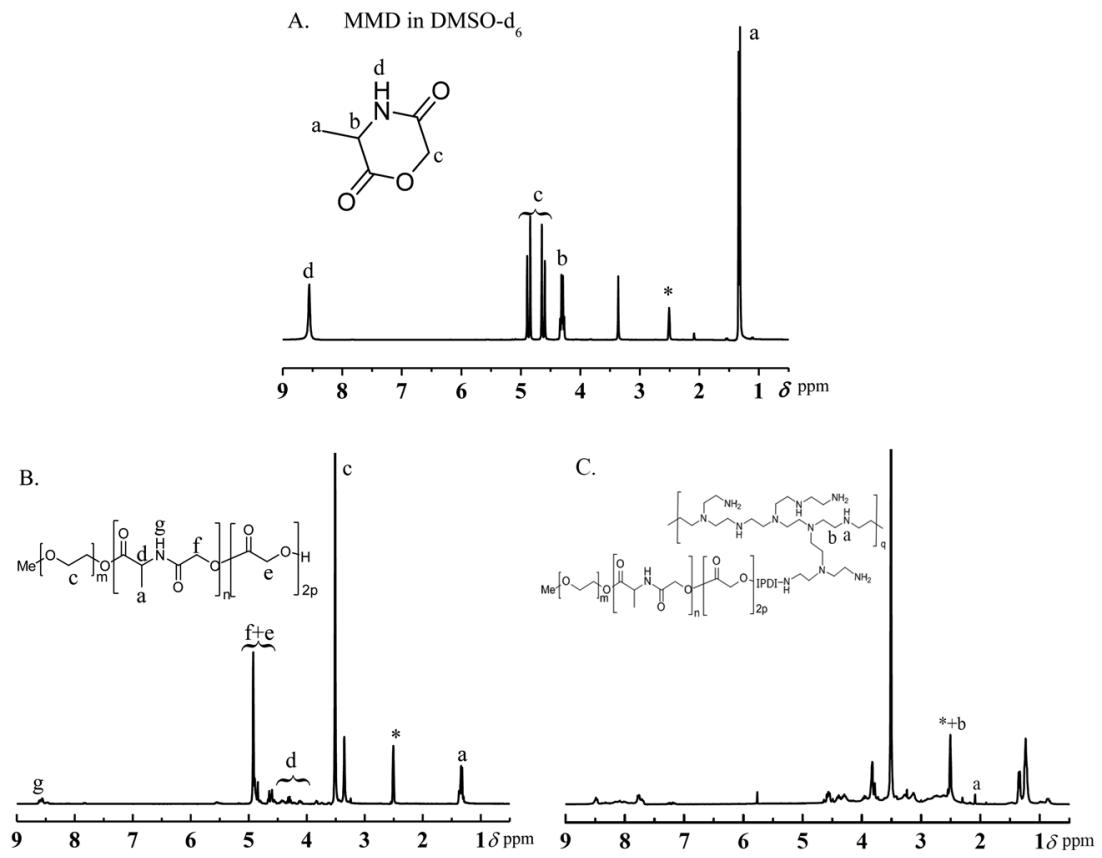

Fig. $2{ }^{1} \mathrm{H}$ NMR spectra of MMD monomer, diblock copolymer and amphiphilic triblock copolymer in DMSO-d 6 solvent. (A) MMD, (B) mPEG- $b$ $\mathrm{P}(\mathrm{MMD}-\mathrm{co}-\mathrm{GA})_{1}$ diblock copolymer, (C) mPEG-b-P(MMD-co-GA)-g-PEl ${ }_{1}$ triblock copolymer, * solvent peak.

hydrophobic group- modified PEI samples as gene carriers with high transfection efficiency. Xiang et al. ${ }^{66}$ found that the PEI-Bu vector formed by PEI $\left(M_{\mathrm{w}}=800\right)$ linked with carbamate had the properties of low cytotoxicity and high transfection efficiency. In this study, we prepared the microparticles by self-assembly. Every microparticle is formed from many triblock copolymer chains, the hydrophobic core of the MPs acted as a crosslinking point which linked numbers of PEI and PEG chains. Thus, the PEI and PEG chains on the surface of MPs can endow them with high hydrophilicity and high positive charge.

The hydrodynamic diameter and zeta potential of MPs complexes were measured with a nanoparticle size and zeta potential analyzer. The mean size and zeta potential values are summarized in Table 2. The results showed that the size of MPs ranged from 144 to $205 \mathrm{~nm}$ with a reasonable polydispersity index (PDI < 0.4). The chemical composition, the dropping rate and the stirring speed of amphiphilic triblock copolymer solutions during the self-assembly process were the main factors which affected the size and surface charge of MPs. We found that the small MPs (120-145 nm) could be formed with a low polymer solution dropping rate $\left(0.01 \mathrm{~mL} \mathrm{~min}^{-1}\right)$ and slow stirring speed (400 rpm). As shown in Scheme 2, the hydrogen bond was another important factor to account for the size of MPs. The strong hydrogen bonding effect increases the stability of the hydrophobic core, thus resulting in the formation of larger particles. $^{51}$ In the following study, mPEG- $b$-P(MMD-co-GA)- $g$ $\mathrm{PEI}_{2}$ based MPs were used due to their suitable size and positive potential.

MPs/pEGFP-ZNF580 complexes were prepared by mixing the MP solution with pEGFP-ZNF580 plasmid in PBS $(\mathrm{pH}=7.4)$ at room temperature and leaving the mixture to stand for $30 \mathrm{~min}$ to form complexes. The TEM images (Fig. 4) showed that the MPs and MP/pEFGP-ZNF580 complexes (N/P molar ratio $=5$ ) exhibited spherical structures. The MP sizes (about $120 \mathrm{~nm}$ ) measured by TEM were smaller than those obtained by nanoparticle size and zeta potential analyzer. The reason might be because the particle sizes measured by nanoparticle size and zeta potential analyzer were obtained in hydrated state in solution, while those obtained by TEM had been dried after being dropped onto carbon-coated copper meshes.

The formation of MP/pEFGP-ZNF580 complexes with appropriate size (100-200 $\mathrm{nm}$ ) and positive charged surface is an important prerequisite for polycations used as gene carriers. $^{53}$ The size and zeta potential of MP/pEFGP-ZNF580

Table 2 Microparticle size, polydispersity index, zeta potential and CMC values of MPs

\begin{tabular}{lllll}
\hline Sample ID & Size $(\mathrm{nm})$ & $\mathrm{PDI}^{a}$ & $\mathrm{ZP}^{a}(\mathrm{mV})$ & $\mathrm{CMC}^{b}\left(\mu \mathrm{g} \mathrm{mL}{ }^{-1}\right)$ \\
\hline mPEG- $b$-P(MMD-co-GA)-g-PEI & $180 \pm 11.5$ & $0.32 \pm 0.2$ & $22.0 \pm 0.7$ & 0.0079 \\
mPEG- $b$-P(MMD-co-GA)-g-PEI & $144 \pm 9.6$ & $0.36 \pm 0.1$ & $19.8 \pm 0.7$ & 0.0050 \\
mPEG- $b$-P(MMD-co-GA)- $g$-PEI & $205 \pm 28.5$ & $0.20 \pm 0.02$ & $24.5 \pm 1.0$ & 0.0040
\end{tabular}

${ }^{a}$ PDI: polydispersity index; ZP: zeta potential (temperature $=25{ }^{\circ} \mathrm{C}, \mathrm{pH}=7.4$ ). ${ }^{b} \mathrm{CMC}$ : critical micelle concentration, determined in deionized water. 

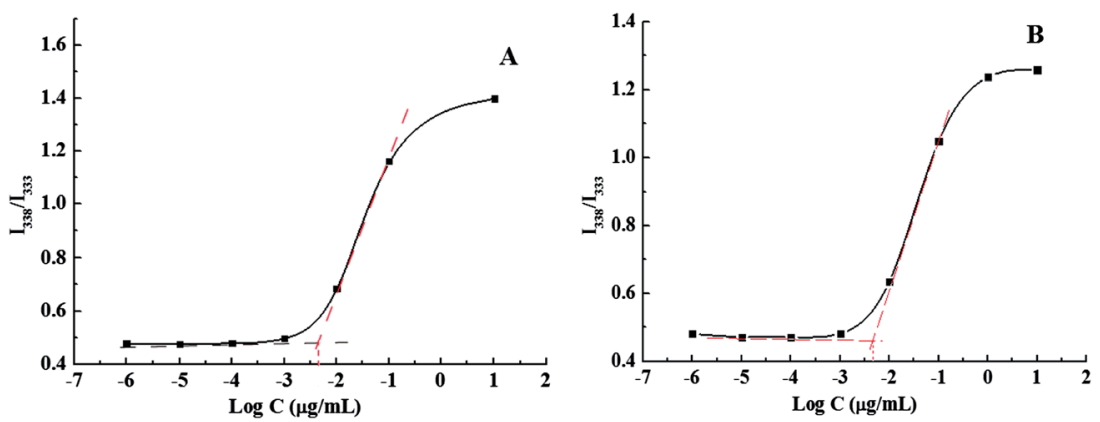

Fig. 3 Fluorescence intensity ratio variation of $/ 338 / / 333$ for pyrene emission against the concentration of amphiphilic triblock copolymers. (A) mPEG- $b-P(M M D-c O-G A)-g-P E I_{1}$, (B) mPEG- $b-P(M M D-c o-G A)-g-P E I_{2}$.

complexes were measured at different $\mathrm{N} / \mathrm{P}$ molar ratios and the results are shown in Fig. 5 . The mPEG- $b$-P(MMD-co-GA)-g-PEI based MPs could efficiently compact pEGFP-ZNF580 into nanosized complexes. The diameter of MP/pEGFP-ZNF580 complexes is $122 \pm 3 \mathrm{~nm}$ at the N/P molar ratio of 10 (Fig. 5A), which is suitable to be applied for endocytic cellular uptake. ${ }^{67}$ The declining trend of the complex sizes is mainly due to the high N/P molar ratio that made the complexes evolve into more compact entities where DNA molecules are highly compressed. ${ }^{68}$ The zeta potential of the complex at different N/P molar ratios presented net positive charges as shown in Fig. 5B; with the increase of $\mathrm{N} / \mathrm{P}$ molar ratio, the net positive charges of the complexes were also increased. Suitable net positive charges on the surface of MPs provide a guarantee for high transfection, because the initial electrostatic interactions between positively charged MP/pEFGP-ZNF580 complexes and negatively charged cell membranes play an important role in the endocytosis. ${ }^{69}$

3.2.3. Agarose gel electrophoresis. Effective condensation of negatively charged pEFGP-ZNF580 into MPs through electrostatic interactions is of great importance for well-designed

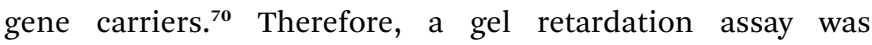
employed to verify the successful binding between mPEG- $b$ $\mathrm{P}(\mathrm{MMD}-c o-\mathrm{GA})-g$ - $\mathrm{PEI}_{2}$ based MPs and pEFGP-ZNF580. As we know, MPs with or without pEFGP-ZNF580 are too large to diffuse through the agarose matrix. Therefore, only pEFGP-

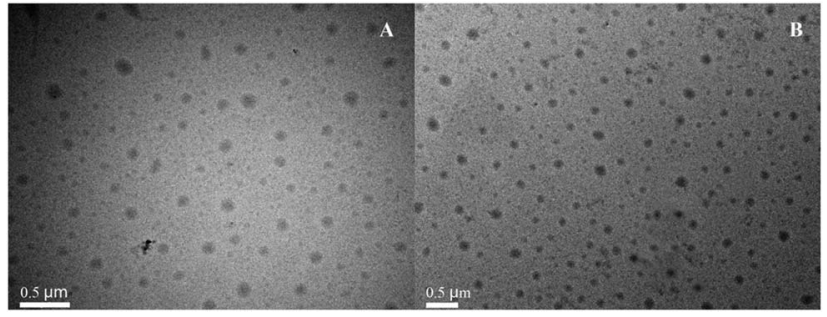

Fig. 4 TEM images of MPs and MP/pEFGP-ZNF580 complexes. (A) MPs formed from mPEG- $b-P(M M D-c O-G A)-g-P E I_{2}$ triblock copolymer, (B) MP/pEFGP-ZNF580 complexes prepared from mPEG- $b$ $P(M M D-C O-G A)-g-P E I_{2}$ and $p E G F P-Z N F 580$

ZNF580 which is not bound onto the surface of MPs is able to migrate to the positive electrode in the same manner as the naked pEFGP-ZNF580. ${ }^{71}$

MP/pEFGP-ZNF580 complexes with different N/P molar ratios were incubated at room temperature for $30 \mathrm{~min}$, before gel retardation assay. The image of gel retardation assay was obtained as shown in Fig. 6. The results indicated that pEFGP-ZNF580s could not bind pEFGP-ZNF580 totally until the N/P molar ratio rose to 5. In the following study, high N/P molar ratio $(\geq 5)$ was selected due to the perfect binding effect.

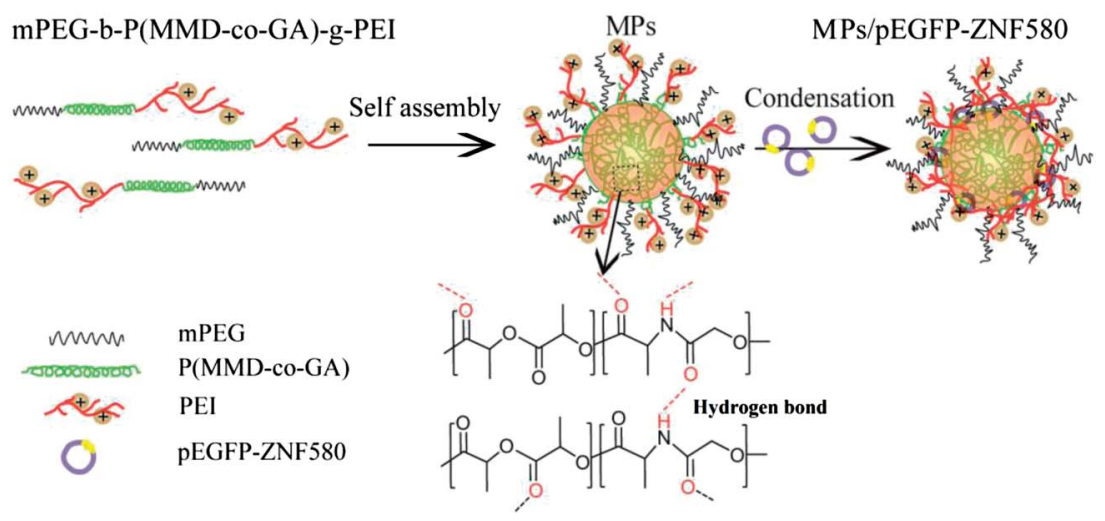

Scheme 2 MPs were prepared by self-assembly of amphiphilic triblock copolymers, and MPs/pEGFP-ZNF580 complexes by self-assembly of amphiphilic triblock copolymers and following condensation with pEGFP-ZNF580. 

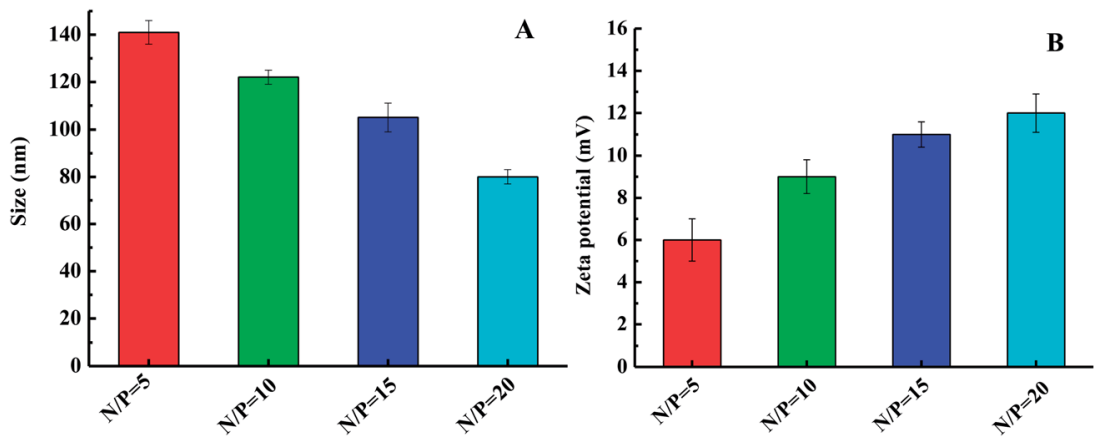

Fig. 5 Microparticle size (A) and zeta potential (B) of mPEG-b-P(MMD-co-GA)-g-PEI 2 MP/pEFGP-ZNF580 complexes at different N/P molar ratios.

3.2.4. In vitro release. It is an important property for gene carriers in gene therapy to obtain an ideal sequential release of gene. ${ }^{23}$ In order to investigate the gene release from MP/pEFGPZNF580 complexes, the in vitro release assay was carried out. As shown in Fig. 7, an initial increase in release was observed for the complexes at different N/P molar ratios and $58.6 \%$ of the pEFGPZNF580 was released from the complexes at the N/P molar ratio of 5 after 7 days. However, when the N/P molar ratio increased to 20 , only $40.3 \%$ of the pEFGP-ZNF580 was released under the same conditions. This reason may be assigned to the electrostatic interaction between MPs and pEFGP-ZNF580 gradually improving with the increase of $\mathrm{N} / \mathrm{P}$ molar ratio. The release of plasmid could be maintained at least for 11 days with the MP/ pEFGP-ZNF580 complexes gene transport system, the release speed of pEFGP-ZNF580 decreased with the increase of the N/P molar ratio. This result indicated that the release of pEFGPZNF580 can be controlled by this gene transport system.

\subsection{Transfection and cytotoxicity}

3.3.1. In vitro transfection. As shown in Scheme 3 , when MP/pEFGP-ZNF580 complexes are cultured with EA.hy926 cells in the growth medium, complexes can be transported into the cells by endocytosis. When MP/pEFGP-ZNF580 complexes are released from endolysosome, pEGFP-ZNF580 could express in the nucleus. In this way, the proliferation of EA.hy926 cells could be promoted greatly.

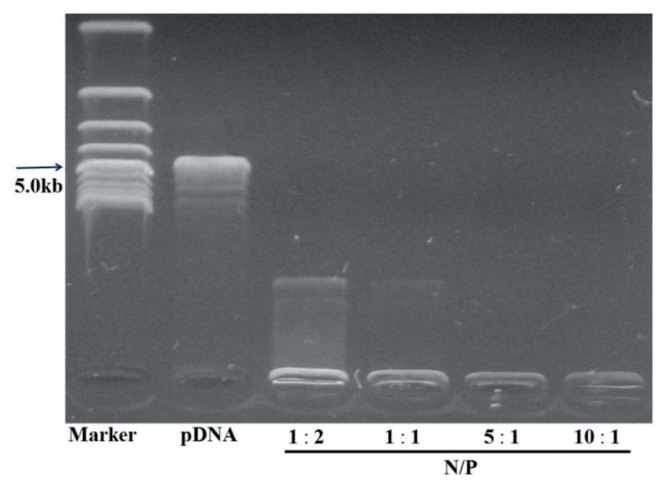

Fig. 6 Agarose gel electrophoresis of MP/pEFGP-ZNF580 complexes at various N/P molar ratios. pDNA is pEFGP-ZNF580.
In order to investigate the gene transfection efficiency of MP/pEFGP-ZNF580 complexes in vitro, EA.hy926 cells were transfected with the complexes of MP/pEFGP-ZNF580 at different N/P molar ratios using the same concentration $(30 \mu \mathrm{g}$ pEFGP-ZNF580 complexes per volume medium (mL)). Cells treated with Lipofectamine ${ }^{\mathrm{TM}} 2000$ were used as the positive control, and cells without treatment as the negative control. Green fluorescence images of the EA.hy926 cells at different time points were taken by an inverted fluorescence microscope. After 48 hours a large proportion of cells with green fluorescence could be observed by an inverted fluorescence microscope (Fig. 8), which indicated that the plasmids had been transfected and expressed successfully in EA.hy926 cells.

In order to quantitatively analyze the expression of ZNF580 gene in normal cells and cells transfected by MP/pEFGPZNF580 complexes and Lipofectamine ${ }^{\mathrm{TM}}$ 2000, western bolt detection was used to reveal the expression of ZNF580. The EA.hy926 cells were transfected with MP/pEFGP-ZNF580 complexes and Lipofectamine ${ }^{\mathrm{TM}} 2000$ (Fig. 9). After 48 hours, ZNF580 relative protein level (\%) was elevated obviously due to the expression of pEGFP-ZNF580 in transfected cells compared with that of the control group cells $(p<0.05)$. The transfection efficiency of the complexes at the N/P molar ratio of 10 was the best in the experiment conditions. These results indicated that ZNF580 genes were expressed successfully after being released from MP/pEFGP-ZNF580 complexes.

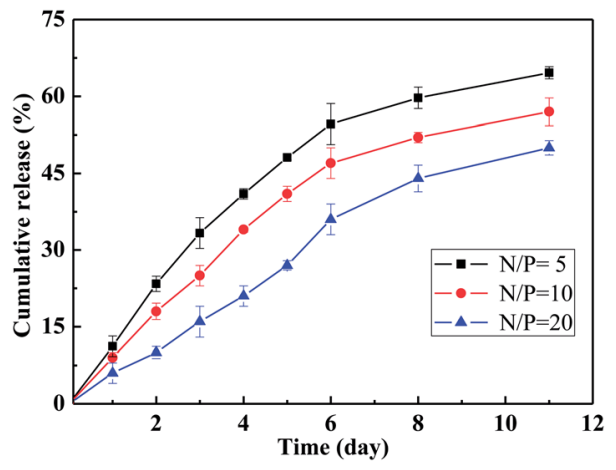

Fig. 7 Cumulative release of pEFGP-ZNF580 from MP/pEFGPZNF580 complexes at different N/P molar ratios in Tris- $\mathrm{HCl}$ buffer $(\mathrm{pH}=7.4)$ at $37^{\circ} \mathrm{C}$. 


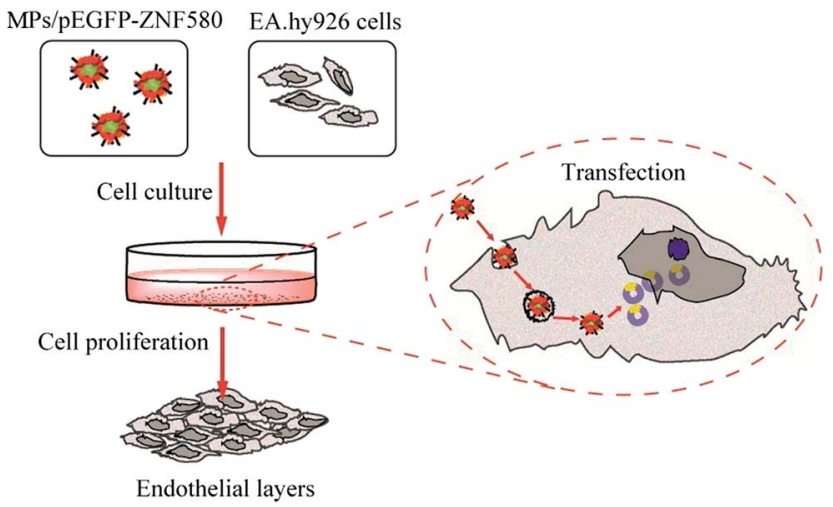

Scheme 3 The process of transfection and proliferation mediated by MP/pEFGP-ZNF580 complexes.

3.3.2. In vitro cytotoxicity. The cytotoxicity associated with PEI based MPs has been a concern as a gene carrier. Herein, the toxicity of mPEG- $b$-P(MMD-co-GA)- $g$-PEI ${ }_{2}$ MPs and MP/ pEFGP-ZNF580 complexes were evaluated by MTT assay using PEI $\left(M_{\mathrm{w}}=1800\right)$ as a control group. As shown in Fig. 10, the relative cell viability of MPs and MP/pEFGP-ZNF580 complexes was much higher than PEI at the same concentration; and the cytotoxicity of the MP/pEFGP-ZNF580 complexes was relatively lower than that of the MPs at the same concentration.

MP/pEFGP-ZNF580 complexes only showed mild cytotoxicity (cell viability $>80 \%$ ) even at the high concentration $(80 \mu \mathrm{g}$ $\mathrm{mL}^{-1}$ ). This phenomenon can be explained by the neutralization between positive and negative charges. ${ }^{72,73}$ When pEFGPZNF580s were adsorbed to the surface of MPs, the positive charges of PEI were partly neutralized by the negative charges of pEFGP-ZNF580s, which minimize the direct contact of the positive charge with the cell membrane, ${ }^{74}$ this is the main reason for the low toxicity of MP/pEFGP-ZNF580 complexes. ${ }^{75}$

Low cytotoxicity is one of the prerequisites for in vivo application of polymeric gene carriers. We excitedly demonstrated that the MPs and MP/pEFGP-ZNF580 complexes at low

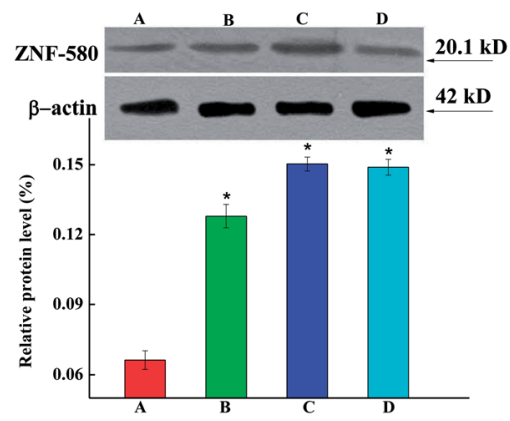

Fig. 9 Western blot analysis for ZNF580 protein expression in EA.hy926 cells transfected by MP/pEFGP-ZNF580 complexes and Lipofectamine $^{T M} 2000$ after 48 hours. (A) EA.hy926 as the control group cells, (B) cells transfected by MP/pEFGP-ZNF580 complexes $(\mathrm{N} / \mathrm{P}$ molar ratio $=5)$, $(\mathrm{C})$ cells transfected by MP/pEFGP-ZNF580 complexes (N/P molar ratio $=10$ ), (D) cells transfected transiently by Lipofectamine $^{\text {TM }} 2000$ ( $\bar{x}+\mathrm{SD}, n=3, * p<0.05$ vs. A group).

concentration $\left(10 \mu \mathrm{g} \mathrm{mL^{-1 }}\right)$ not only exhibited non-cytotoxicity, but also promoted the cell proliferation. The main reason is that the introduction of PEG chains which formed a hydration layer on the surface of $\mathrm{MPs}^{76}$ and at the same time the degradation product (L-alanine) released from the hydrophobic core might stimulate the proliferation of ECs via a signal pathway. ${ }^{77}$ These results manifested that the MPEG- $b-\mathrm{P}(\mathrm{MMD}-\mathrm{co}-\mathrm{GA})-g-\mathrm{PEI}_{2}$ based MPs could be a suitable gene carrier with non-cytotoxicity.

\subsection{Cell migration}

Cell migration and proliferation play vital roles in the wound healing process; the scratch assay has been used to study proliferation/migration properties of different cell lines, ${ }^{57}$ and is an experimentally well-developed and easy protocol for analyzing cell migration in vitro. ${ }^{78}$ EA.hy926 cells were transfected with MP/pEFGP-ZNF580 complexes at the N/P molar ratio of 10. After 48 hours, a monolayer of EA.hy926 cells was formed in a 6-well plate in vitro. An artificial scratch with parallel borders was mechanically created as shown in
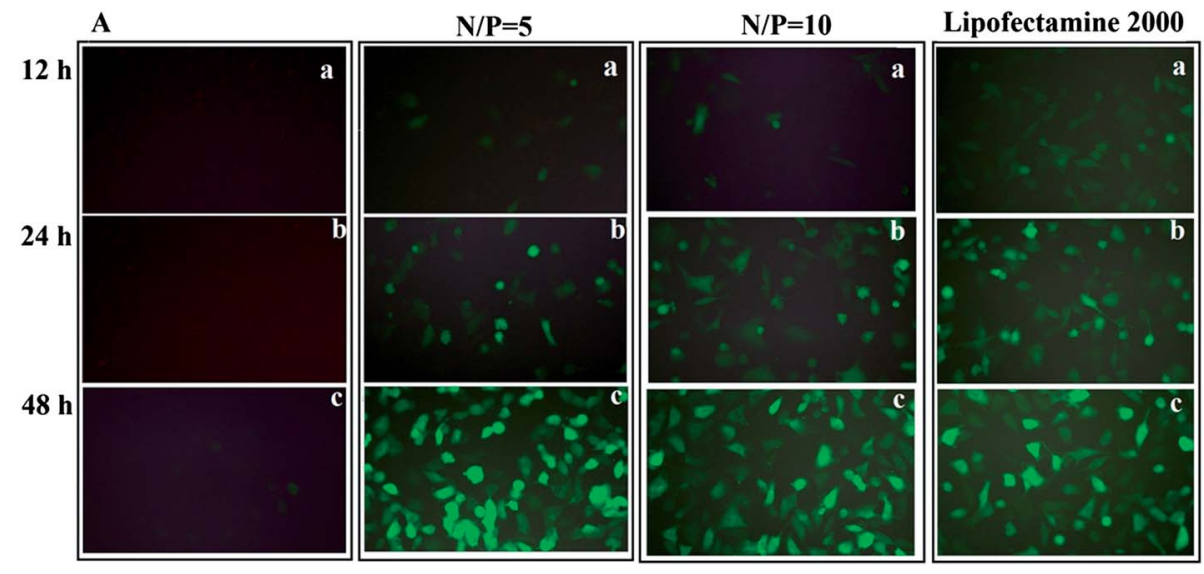

Fig. 8 Fluorescence images of EA.hy926 cells transfected by MP/pEFGP-ZNF580 complexes at different N/P molar ratios and time intervals of 12 hours (a), 24 hours (b) and 48 hours (c). Lipofectamine ${ }^{T M} 2000$ group is the positive control group, (A) cells without treatment with MP/pEFGPZNF580 and Lipofectamine ${ }^{T M} 2000$ served as the negative control group. 


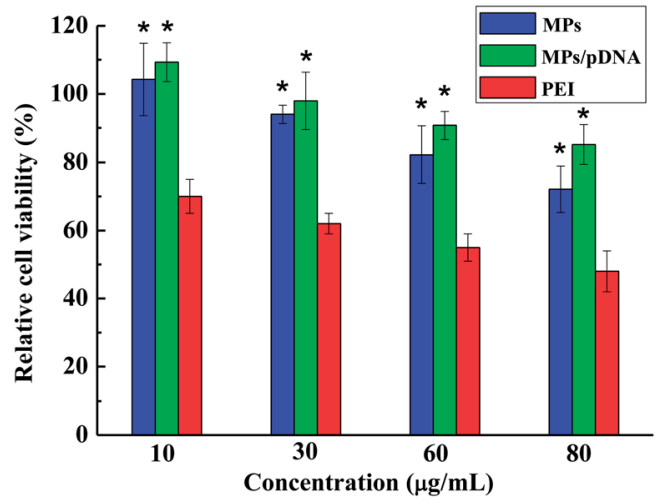

Fig. 10 Relative cell viability of EA.hy926 cells after 48 hours of treatment with different concentrations of MPs and MP/pEFGPZNF580 complexes at a N/P molar ratio of $10(\bar{x}+\mathrm{SD}, n=6$, $* p<0.05$ vs. PEl group), PEI $\left(M_{w}=1800\right)$ as a control group.

Fig. $11 \mathrm{~A}(\mathrm{a})$. Subsequently, the cells migrated to close this "wound" scratch, the time course of the migration process at different time intervals was monitored by capturing images, and the migration area was calculated by Image-Pro Plus (6.0).

Our study demonstrated a significant effect of MP/pEFGPZNF580 complexes on the proliferation and migration of ECs.
After 12 hours, the migration area of cells transfected by MP/ pEFGP-ZNF580 complexes increased to $78 \pm 6.1 \%$, while that of cells transfected by Lipofectamine ${ }^{\mathrm{TM}} 2000$ reagent (the control group) only increased to $72 \pm 5.5 \%$. These results suggested that MP/pEFGP-ZNF580 complexes have great potential to promote EC migration and proliferation.

\section{Discussion}

Rapid endothelialization is one of the effective methods to create an anti-thrombogenic surface of artificial blood vessels. ${ }^{79}$ In the present study, a novel gene carrier with low toxicity was prepared; the ZNF580 gene was carried by MPs into ECs for the first time and realized high transfection efficacy.

A non-toxic and efficient carrier is the base of gene delivery, and many researches focused on the development of magnetic MPs. Yoo et al. $^{80}$ reported that nanoparticles modified with PEI $\left(M_{\mathrm{w}}=1800\right)$ and folic acid had low toxicity to KB and WI-38 cells, and the magnetic MP/pDNA complexes had reasonable transfection effect on $\mathrm{KB}$ cells. In the magnetic iron oxide nanoparticles, the iron oxide acted as the important core as a crosslinking point, which connected PEI, PEG, antibacterial $N$-halamine ${ }^{81}$ and RGD peptides ${ }^{82}$ etc. to form a multifunctional nanoparticle. However, iron oxide nanoparticles have recently

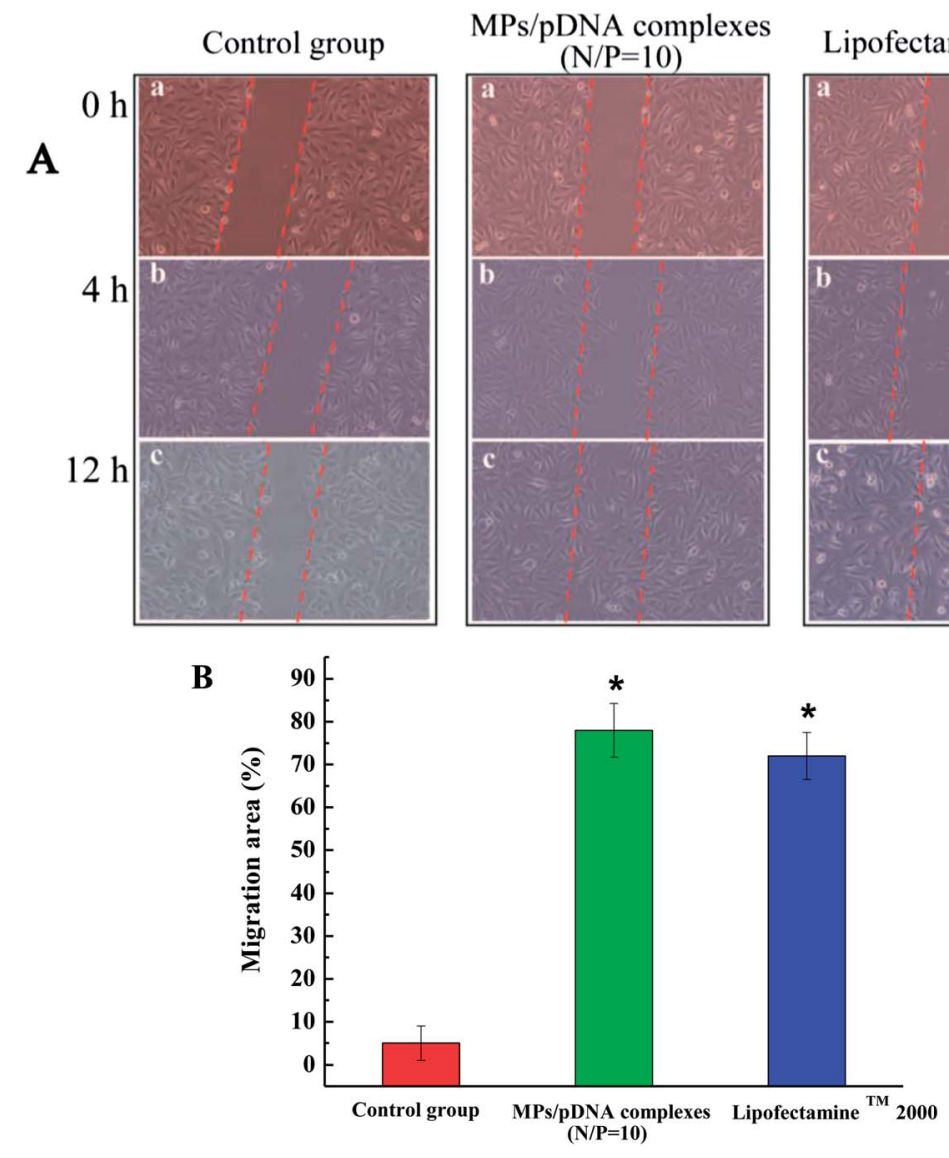

Fig. 11 Migration process of EA.hy926 cells at different time points and migration area after 12 hours. (A) Migration process of EA.hy926 cells at 0 hours (photos a), 4 hours (photos b), 12 hours (photos c); (B) migration area (\%) after 12 hours calculated by Image-Pro Plus (6.0) $(\bar{x}+$ SD, $n=3$, $* p<0.05$ vs. control group). 
been found to have concentration-dependent cytotoxicity. ${ }^{83}$ The structure of magnetic nanoparticles is an inspiration for us to prepare low toxicity MPs with a biodegradable polymer core. Non-toxic biodegradable polymers might be used as the core to overcome the disadvantage of magnetic nanoparticles.

In the present study, with great interest, we synthesized novel amphiphilic triblock mPEG- $b$-P(MMD-co-GA)- $g$-PEI copolymers from mPEG MMD, GA and PEI. Through ROP, mPEG- $b$-P(MMD-co-GA) diblock copolymers were prepared using hydrophilic mPEG as the initiator. After the grafting of PEI, amphiphilic triblock copolymers were obtained finally.

The self-assembly process employed to prepare the MPs from these triblock copolymers was the most common and convenient technique. Herein, the hydrophobic core of a single microparticle contained many $\mathrm{P}(\mathrm{MMD}-\mathrm{co}-\mathrm{GA})$ segments of these copolymers. The function of the hydrophobic core is like the crosslinking point as previously reported. ${ }^{84}$ In this way, many short PEI $\left(M_{\mathrm{w}}=1800\right)$ and PEG $\left(M_{\mathrm{w}}=5000\right)$ chains were linked on the surface of MPs. The quantity of PEI chains was the key factor for the high transfection effect. Although PEI $\left(M_{\mathrm{w}}=1800\right)$ could not condense DNA effectively, many short PEI $\left(M_{\mathrm{w}}=1800\right)$ chains were connected with the core of a microparticle, which showed a reasonable transfection effect as high molecular weight PEI. PEG chains were used to increase the hydrophilicity of the MPs and also reduce the toxicity.

The cytotoxicity of the novel gene carrier and the MP/pEGFPZNF580 complexes was very low (cell viability $>80 \%$ ) at the concentration of $80 \mu \mathrm{g} \mathrm{mL} \mathrm{mL}^{-1}$ after 48 hours, this result indicated the cytotoxicity was decreased greatly by introducing the PEG and short PEI chains on the surface of MPs. The novel gene carrier could completely condense the pEGFP-ZNF580 onto its surface to form MP/pEGFP-ZNF580 complexes at the N/P molar ratio of 5. Thus the pEGFP-ZNF580 gene could be taken into ECs through endocytosis. After release and expression, ZNF580 promoted the proliferation and migration of ECs significantly. The transfection effect of MP/pEGFP-ZNF580 complexes (N/P molar ratio $=10$ ) was as high as the Lipofectamine ${ }^{\mathrm{TM}} 2000$ reagent. These results indicated that the quantity of PEI chains which linked with the hydrophobic core was suitable for high transfection effect. The proliferation of ECs could even be promoted by the degradation products of the gene carrier at a reasonable concentration. The sequential release of pEGFPZNF580 from MP/pEGFP-ZNF580 complexes could be maintained for at least 11 days.

\section{Conclusion}

In this study, we synthesized amphiphilic triblock copolymers and prepared novel biodegradable microparticles from them. pEGFP-ZNF580 gene was carried into ECs by these microparticles with suitable diameter and positive charge; the proliferation and migration of ECs were improved significantly by the expression of pEGFP-ZNF580 gene. This study provides an effective method for the development of a low cytotoxicity nonviral gene delivery system to promote the proliferation and migration of ECs by ZNF580 gene.

\section{Acknowledgements}

This project was supported by the National Natural Science Foundation of China (Grant no. 31370969, 51073119, 31271016), the International Cooperation from Ministry of Science and Technology of China (Grant no. 2013DFG52040, 2008DFA51170), Ph.D. Programs Foundation of Ministry of Education of China (no. 20120032110073) and the Program of Introducing Talents of Discipline to Universities of China (no. B06006).

\section{Notes and references}

1 B. H. Oh, R. W. M. Kaligis, Y. Wang, F. E. R. Punzalan, N. C. Suwanwela, V. L. Nguyen, T. H. Lee, K. H. Sim, Y. Itoh, N. Bahadur and J. Leong, Int. J. Cardiol., 2013, 168, 2761.

2 J. J. Hu, W. C. Chao, P. Y. Lee and C. H. Huang, J. Mech. Behav. Biomed. Mater., 2012, 13, 140.

3 W. Zheng, Z. Wang, L. Song, Q. Zhao, J. Zhang, D. Li, S. Wang, J. Han, X. L. Zheng, Z. Yang and D. Kong, Biomaterials, 2012, 33, 2880.

4 M. J. Smith, M. J. Mcclure, S. A. Sell, C. P. Barnes, B. H. Walpoth, D. G. Simpson and G. L. Bowlin, Acta Biomater., 2008, 4, 58.

5 H. Wang, Y. Feng, Z. Fang, W. Yuan and M. Khan, Mater. Sci. Eng., C, 2012, 32, 2306.

6 R. Y. Kannan, H. J. Salacinski, P. E. Butler, G. Hamilton and A. M. Seifalian, J. Biomed. Mater. Res., Part B, 2005, 74B, 570.

7 P. D'Arrigo, C. Giordano, P. Macchi, L. Malpezzi, G. Pedrocchi-Fantoni and S. Servi, Int. J. Artif. Organs, 2007, 30, 133.

8 B. W. Tillman, S. K. Yazdani, S. J. Lee, R. L. Geary, A. Atala and J. J. Yoo, Biomaterials, 2009, 30, 583.

9 J. Yu, A. Wang, Z. Tang, J. Henry, B. Li-Ping Lee, Y. Zhu, F. Yuan, F. Huang and S. Li, Biomaterials, 2012, 33, 8062.

10 J. Zhu, Biomaterials, 2010, 31, 4639.

11 B. Gao, Y. Feng, J. Lu, L. Zhang, M. Zhao, C. Shi, M. Khan and J. Guo, Mater. Sci. Eng., C, 2013, 33, 2871.

12 H. Zhao, Y. Feng and J. Guo, J. Appl. Polym. Sci., 2011, 119, 3717.

13 Y. Feng, D. Yang, M. Behl, A. Lendlein, H. Zhao and J. Guo, Macromol. Symp., 2011, 309-310, 6.

14 H. Wang, Y. Feng, M. Behl, A. Lendlein, H. Zhao, R. Xiao, J. Lu, L. Zhang and J. Guo, Front. Chem. Sci. Eng., 2011, 5, 392.

15 H. Wang, Y. Feng, H. Zhao, Z. Fang, M. Khan and J. Guo, J. Nanosci. Nanotechnol., 2013, 13, 1578.

16 Y. Feng, Z. Fang, H. Wang and J. Guo, Trans. Tianjin Univ., 2013, 19, 182.

17 H. Zhang, X. Jia, F. Han, J. Zhao, Y. Zhao, Y. Fan and X. Yuan, Biomaterials, 2013, 34, 2202.

18 Q. Lin, X. Ding, F. Qiu, X. Song, G. Fu and J. Ji, Biomaterials, 2010, 31, 4017.

19 Y. Zhu, C. Gao, T. He and J. Shen, Biomaterials, 2004, 25, 423. 
20 E. Sulpice, S. Ding, B. Muscatelli-Groux, M. Berge, Z. C. Han, J. Plouet, G. Tobelem and T. Merkulova-Rainon, Biol. Cell, 2009, 101, 525.

21 R. Adya, B. K. Tan, A. Punn, J. Chen and H. S. Randeva, Cardiovasc. Res., 2008, 78, 356.

22 N. Swanson, K. Hogrefe, Q. Javed and A. H. Gershlick, Int. J. Cardiol., 2003, 92, 247.

23 J. Yang, Y. Zeng, C. Zhang, Y. X. Chen, Z. Yang, Y. Li, X. Leng, D. Kong, X. Q. Wei, H. F. Sun and C. X. Song, Biomaterials, 2013, 34, 1635.

24 S. Takabatake, T. Tsubokawa, T. Matsuda and M. Yamagishi, J. Am. Coll. Cardiol., 2012, 59, E334.

25 D. L. Ren, H. K. Wang, J. Q. Liu, M. H. Zhang and W. C. Zhang, Mol. Cell. Biochem., 2011, 359, 183.

26 H. Y. Sun, S. P. Wei, R. C. Xu, P. X. Xu and W. C. Zhang, Biochem. Biophys. Res. Commun., 2010, 395, 361.

27 A. Fischer, S. Hacein-Bey-Abina and M. Cavazzana-Calvo, Nat. Immunol., 2010, 11, 457.

28 G. Collet, C. Grillon, M. Nadim and C. Kieda, Gene, 2013, 525, 208.

29 Y. He, G. Cheng, L. Xie, Y. Nie, B. He and Z. Gu, Biomaterials, 2013, 34, 1235.

30 J. Ye, H. He, J. Gong, W. Dong, Y. Huang, J. Wang, G. Chen and V. Yang, Front. Chem. Sci. Eng., 2013, 7, 20.

31 U. Lächelt and E. Wagner, Front. Chem. Sci. Eng., 2011, 5, 275.

32 Z. Liu, Z. Zhang, C. Zhou and Y. Jiao, Prog. Polym. Sci., 2010, 35,1144 .

33 R. Kircheis, L. Wightman and E. Wagner, Adv. Drug Delivery Rev., 2001, 53, 341.

34 A. M. Funhoff, C. F. van Nostrum, M. C. Lok, M. M. Fretz, D. J. Crommelin and W. E. Hennink, Bioconjugate Chem., 2004, 15, 1212.

35 J. Sun, F. Zeng, H. Jian and S. Wu, Biomacromolecules, 2013, 14, 728 .

36 J. Sun, F. Zeng, H. Jian and S. Wu, Polym. Chem., 2013, 4, 5810.

37 A. Calarco, M. Bosetti, S. Margarucci, L. Fusaro, E. Nicoli, O. Petillo, M. Cannas, U. Galderisi and G. Peluso, Toxicol. Lett. , 2013, 218, 10.

38 A. Zintchenko, A. Philipp, A. Dehshahri and E. Wagner, Bioconjugate Chem., 2008, 19, 1448.

39 S. Nimesh, A. Aggarwal, P. Kumar, Y. Singh, K. C. Gupta and R. Chandra, Int. J. Pharm., 2007, 337, 265.

40 A. M. Doody, J. N. Korley, K. P. Dang, P. N. Zawaneh and D. Putnam, J. Controlled Release, 2006, 116, 227.

41 A. Swami, R. K. Kurupati, A. Pathak, Y. Singh, P. Kumar and K. C. Gupta, Biochem. Biophys. Res. Commun., 2007, 362, 835.

42 W. T. Godbey, K. K. Wu and A. G. Mikos, J. Biomed. Mater. Res., 1999, 45, 268.

43 K. Wong, G. Sun, X. Zhang, H. Dai, Y. Liu, C. He and K. W. Leong, Bioconjugate Chem., 2006, 17, 152.

44 M. L. Forrest, J. T. Koerber and D. W. Pack, Bioconjugate Chem., 2003, 14, 934.

45 Z. Zhang, C. Yang, Y. Duan, Y. Wang, J. Liu, L. Wang and D. Kong, Acta Biomater., 2010, 6, 2650.
46 C. A. Nguyen, E. Allemann, G. Schwach, E. Doelker and R. Gurny, Int. J. Pharm., 2003, 254, 69.

47 Z. Zhang, J. Ni, L. Chen, L. Yu, J. Xu and J. Ding, Biomaterials, 2011, 32, 4725.

48 V. Pavlovic, E. Cherneva, D. Yancheva and A. Smelcerovic, Food Chem. Toxicol., 2012, 50, 3014.

49 X. Yao, R. Peng and J. Ding, Adv. Mater., 2013, 25, 5257.

50 Y. Feng, C. Chen, L. Zhang, H. Tian and W. Yuan, Trans. Tianjin Univ., 2012, 18, 315.

51 Y. Zhao, J. Li, H. Yu, G. Wang and W. Liu, Int. J. Pharm., 2012, 430, 282.

52 C. J. Chen, J. C. Wang, E. Y. Zhao, L. Y. Gao, Q. Feng, X. Y. Liu, Z. X. Zhao, X. F. Ma, W. J. Hou, L. R. Zhang, W. L. Lu and Q. Zhang, Biomaterials, 2013, 34, 5303.

53 S. Guo, Y. Huang, T. Wei, W. Zhang, W. Wang, D. Lin, X. Zhang, A. Kumar, Q. Du, J. Xing, L. Deng, Z. Liang, P. C. Wang, A. Dong and X. J. Liang, Biomaterials, 2011, 32, 879. 54 A. S. Ivessa, Methods Mol. Biol., 2013, 1054, 83.

55 M. Gargouri, A. Sapin, B. Arica-Yegin, J. L. Merlin, P. Becuwe and P. Maincent, Int. J. Pharm., 2011, 403, 276.

56 Q. Cheng, Y. Huang, H. Zheng, T. Wei, S. Zheng, S. Huo, X. Wang, Q. Du, X. Zhang, H. Y. Zhang, X. J. Liang, C. Wang, R. Tang and Z. Liang, Biomaterials, 2013, 34, 3120. 57 M. Zubair, A. Ekholm, H. Nybom, S. Renvert, C. Widen and K. Rumpunen, J. Ethnopharmacol., 2012, 141, 825.

58 W. C. Hung and H. C. Chang, J. Agric. Food Chem., 2009, 57, 76.

59 J. Wu, Z. Mao and C. Gao, Biomaterials, 2012, 33, 810.

60 A. N. Ford Versypt, D. W. Pack and R. D. Braatz, J. Controlled Release, 2013, 165, 29.

61 L. Zhang, Y. Feng, H. Tian, C. Shi, M. Zhao and J. Guo, React. Funct. Polym., 2013, 73, 1281.

62 H. M. Burt, X. Zhang, P. Toleikis, L. Embree and W. L. Hunter, Colloids Surf., B, 1999, 16, 161.

63 I. Szleifer, Biophys. J., 1997, 72, 595.

64 T. Merdan, K. Kunath, H. Petersen, U. Bakowsky, K. H. Voigt, J. Kopecek and T. Kissel, Bioconjugate Chem., 2005, 16, 785.

65 P. Y. Teo, C. Yang, J. L. Hedrick, A. C. Engler, D. J. Coady, S. Ghaem-Maghami, A. J. George and Y. Y. Yang, Biomaterials, 2013, 34, 7971.

66 S. Xiang, J. Su, H. Tong, F. Yang, W. Tong, W. Yuan, F. Wu, C. Wang, T. Jin, K. Dai and X. Zhang, Biomaterials, 2012, 33, 6520.

67 R. Arote, T. H. Kim, Y. K. Kim, S. K. Hwang, H. L. Jiang, H. H. Song, J. W. Nah, M. H. Cho and C. S. Cho, Biomaterials, 2007, 28, 735.

68 J. Yang, P. Zhang, L. Tang, P. Sun, W. Liu, A. Zuo and D. Liang, Biomaterials, 2010, 31, 144.

69 S. H. Lee, K. H. Bae, S. H. Kim, K. R. Lee and T. G. Park, Int. J. Pharm., 2008, 364, 94.

70 Q. F. Zhang, W. J. Yi, B. Wang, J. Zhang, L. Ren, Q. M. Chen, L. Guo and X. Q. Yu, Biomaterials, 2013, 34, 5391.

71 M. Elfinger, C. Pfeifer, S. Uezguen, M. M. Golas, B. Sander, C. Maucksch, H. Stark, M. K. Aneja and C. Rudolph, Biomacromolecules, 2009, 10, 2912.

72 A. Bonincontro, C. La Mesa, C. Proietti and G. Risuleo, Biomacromolecules, 2007, 8, 1824. 
73 A. F. Jorge, R. S. Dias, J. C. Pereira and A. A. C. C. Pais, Biomacromolecules, 2010, 11, 2399.

74 X. Zhao, Z. Li, H. Pan, W. Liu, M. Lv, F. Leung and W. W. Lu, Acta Biomater., 2013, 9, 6694.

75 K. Kunath, J. Controlled Release, 2003, 89, 113.

76 C. Schweiger, C. Pietzonka, J. Heverhagen and T. Kissel, Int. J. Pharm., 2011, 408, 130.

77 B. Hägglund and G. Sandberg, Immunobiology, 1993, 188, 62.

78 C. C. Liang, A. Y. Park and J. L. Guan, Nat. Protoc., 2007, 2, 329.

79 T. Y. Kang, J. M. Hong, B. J. Kim, H. J. Cha and D. W. Cho, Acta Biomater., 2013, 9, 4716.
80 H. Yoo, S. K. Moon, T. Hwang, Y. S. Kim, J. H. Kim, S. W. Choi and J. H. Kim, Langmuir, 2013, 29, 5962.

81 A. Dong, S. Lan, J. Huang, T. Wang, T. Zhao, L. Xiao, W. Wang, X. Zheng, F. Liu, G. Gao and Y. Chen, ACS Appl. Mater. Interfaces, 2011, 3, 4228.

82 P. C. Wu, C. H. Su, F. Y. Cheng, J. C. Weng, J. H. Chen, T. L. Tsai, C. S. Yeh, W. C. Su, J. R. Hwu, Y. Tzeng and D.-B. Shieh, Bioconjugate Chem., 2008, 19, 1972.

83 Z. Chen, J. J. Yin, Y. T. Zhou, Y. Zhang, L. Song, M. Song, S. Hu and N. Gu, ACS Nano, 2012, 6, 4001.

84 S. H. Yuk, K. S. Oh, S. H. Cho, B. S. Lee, S. Y. Kim, B. K. Kwak, K. Kim and I. C. Kwon, Biomacromolecules, 2011, 12, 2335. 